\title{
Mediatization theory: What is in it for the philosophy of communication? On Stig Hjarvard's The Mediatization of Culture and Society
}

\section{Carlos M. Roos}

Centre for Cinema and Media Studies CIMS, Ghent University Institute for Philosophy, Leiden University

\section{Copyright Notice:}

The present text is originally published in Empedocles: European Journal for the Philosophy of Communication vol. 6.1 (2015), pp. 91-103. Copyright C.M. Roos. It is the same post-print version sent to Intellect LTD (publisher), except that bibliographical references have been corrected. This material is made public via Green Open Access. Contributors to all Intellect journals can deposit their post-print file in institutional repositories or on a personal website. Post-print refers to the version of the paper after peer-review, with revisions having been made but before copy-editing and typesetting have taken place. There is no embargo period so authors can post files as soon as the article has been published. Full text version of the article on IngentaConnect.

For purposes of citation, please refer to the journal version:

Roos, C. M. (2015), 'Mediatization theory: What is in it for the philosophy of communication? On Stig Hjarvard's The Mediatization of Culture and Society', Empedocles: European Journal for the Philosophy of Communication, 6: 1, pp. 91-103, doi: 10.1386/ejpc.6.1.91_1 


\title{
Mediatization theory: What is in it for the philosophy of communication? On Stig Hjarvard's The Mediatization of Culture and Society
}

\author{
Carlos M. Roos \\ Ghent University and Leiden University.
}

\begin{abstract}
The present essay advances a critical assessment of Hjarvard's 2013 work The Mediatization of Culture and Society with an emphasis on its valuable contribution to the philosophy of communication and its current debates. The examination focuses on three specific aspects: first, the epistemological advantages of middlerange theorization over micro and macro levels of analysis; second, the usefulness of mediatization as groundwork for a critique of postmodern media theory; third, the ontic features of technology as the spatiotemporal bender of communication and action today.
\end{abstract}

\section{Keywords}

mediatization institution meso level postmodern theory technology affordances

The concept of mediatization resonates strongly with a number of philosophical discussions about communication in the widest sense. Empedocles, among other scholarly journals, has served as a forum for dwelling on the matter with a focus on the processual aspects of the media vis-à-vis social interaction (Meitz 2012; also Couldry and Hepp 2013; Hepp, Hjarvard and Lundby 2010, Hjarvard and Petersen 2013). Even though the relevance of that approach is undisputable, I am persuaded that the scope of mediatization for analytical and critical purposes decidedly transcends the traditional boundaries of media research. Or, as Adolf maintains, it 'requires the expansion of the terrain of media and communication studies' (2012: 155) towards universes of discourse previously underexplored. The present essay attempts to point out some possible directions in which philosophically informed discussions involving mediatization could move, taking Stig Hjarvard's institutional approach as the point of departure.

With The Mediatization of Culture and Society (2013), Hjarvard puts together the fundamentals of a theory in the making since the 1990s and effectively introduced in the 2000s to the Anglophone scholarly debates. Although the term mediatization did not make it to Hjarvard's headings until 2004 - in occasion of his discussion of the global toy industry (Hjarvard 2004a) - the core ideas behind it can be traced back, at least, to his academic pursuits at the University of Copenhagen as the head of the Global Media Cultures Research Program (Hjarvard 1999). It was not until 2008, however, that Hjarvard's view on mediatization as the process whereby the media and other social institutions become reciprocally dependent reached full theoretical systematization through the publication of En verden af medier (2008a) and 'The Mediatization 
of Society: A theory of the media as agents of social and cultural change' (2008b) - for the English-speaking audience.

The book partially reproduces the organization of its Danish homologue, though excludes the (interesting) discussion on language (2008a: 123-154; see 2004b) and includes an introduction and an epilogue pertinently flanking the main corpus of the volume. The table of contents lists seven chapters, along which Hjarvard introduces and discusses the core elements of mediatization theory with a view to the analysis of actual social phenomena. In the course of the exposition, mediatization is defined against the background of two seminal traditions in media and communication studies, namely the effect paradigm and the audience research paradigm. The distinction between these and Hjarvard's position hinges on the argument that, whereas the former rest on 'the use of media for communicating meaning', i.e. mediation, mediatization theory aims to long-lasting structural transformations where the media play a determining institutional role in social and cultural praxis (Hjarvard 2013: 2). In what follows, I shall look into critical avenues of inquiry enabled by this far reaching approach - one that treats media and communication processes not as discrete objects of study, but rather as explanatory grounds for discerning human experience at large.

\section{The meso level of analysis}

The first aspect I shall refer to is meta-theoretical in nature, and has to do with the balance between the generality and the specificity of claims raised along the way of any academic inquiry. Hjarvard makes clear from the outset that the explanatory scope of mediatization corresponds to a middle-range theory, or as he also calls it, to a meso level of analysis (2013: 4, 11-14, 153ff). In this regard, the author argues for a mode of theory building meant to deliver research from both over-generalizations and under-theorization. Such middle ground is reached by way of a well-gauged combination of fundamental theorization and empirical analysis attentive to the specificities of the phenomena under consideration. Mediatization, by its own relational character, helps sensitize the concepts quickened by the eye of the analytical beholder. Therefore, mediatization theory is conceived as an open and exploratory device instead of a closed and strictly defined one. This allows the ontological frameworks and material conditions at work in every situation to permeate theorization in ways that make room for generalizations across socio-historical and socio-cultural contexts with a desirable degree of equanimity (see Jensen 2013: 208-210).

The following example is illustrative. A cine forum was held in March 2014 at Leiden University (the Netherlands) about the volatile situation in the Democratic Republic of Congo, where a civil war of a transnational scope has been devastating the country during recent decades. Interestingly enough, the film programmed for the event was not only about belligerence in Central Africa, but about the manner in which that state of affairs is experienced by the deaf population in the east of the country. That is a game-changer, without a doubt. The title of the motion picture is The Silent Chaos (Spanò 2013b), and its director, Antonio Spanò, comments: 
The Silent Chaos was conceived as a documentary about one of the many ongoing silent wars in the world. However, the initial script has been changed after an unexpected encounter with some deaf guys in Butembo. It was impressive to see that among the population they were those with more yearn to communicate. From that moment it was clear that our way of describing the reality of that place would have changed. We finally found the starting point of the movie.

(Spanò 2013a)

In many senses, theory building is analogous to documentary filmmaking, particularly in that both are narrative gestures about something else. Even in the absence of a plot in the strict sense of the term, fulfilling the will to describe, to explain, or to triangulate a standpoint from where to describe and explain, involves irrevocably the articulation of discourse and therefore an utterer that lets itself be felt in the spatiotemporal organization of the text. That productive moment of organization and shaping, i.e. articulation itself, is indebted to a certain positioning a priori that determines not only the incidental emplacement of the camera, or the strategic selection of the cases for scrutiny, but also the networks of significance from which the story is to be told. That constitutes the true 'starting point' of theorization. Now then, such a genesis is unavoidably twofold. In the film, the peculiar focus on the deaf population in a context hostile to diversity (Spanò 2013a) necessarily determines the narrative outcome on all levels, as does the background of the young director as an Italian filmmaker who has witnessed the struggles of his people and the wars of others throughout his globetrotting career. On the one hand, Spanò's constellation of significances is the ontological foundation that enables his understanding of North Kivu; on the other hand, the Congolese region and its people, deaf and otherwise, is the intentional object of his cinematographic articulation. In a similar vein, when conducting individual studies of politics, religion and play (chapters 3 to 6), Hjarvard tends to choose the narrative standpoint of highly modernized societies in the Euro-American context, in an analytical gesture that simultaneously quickens his own episteme as a Scandinavian sociologist. The meso level of analysis, as introduced in the more theoretical sections of the book, leaves room for adaptation and dialogue, for 'shooting the story' from the perspective that better fits the individual phenomenon at stake - yet without cancelling the episteme to which mediatization theory is originally subscribed.

There is, of course, more to our example than the obvious agency of the (non-)lyrical speaker. During the Q\&A session that followed the screening of The Silent Chaos, Hjarvard's mediatization theory informed an important segment of the discussion. Spanò was asked about the media landscape in North Kivu, in terms of the possibilities for the deaf to circumvent certain inconveniencies with the aid of the digital media. Spanò answered that, apart from the fact that analphabetism is rather common among the population and that electricity is not always available, media communications in the region shrink to non-smartphone-based telephony and a few scattered community radio stations. In his experience, there is a strong oral communication culture at play in the Democratic Republic of Congo, which is precisely one of the reasons why the deaf have it so difficult when it comes to social interaction 
(noteworthy, Spanò's impressions are consistent with recent philosophical elaborations on orality in Sub-Saharan Africa, see Diagne 2005). At this point, mediatization theory was called into question. Via the concept of media logic mobilized in The Mediatization of Culture and Society (2013: 17-18, 44-45; see also Altheide 2012; Altheide and Snow 1979), it would be possible to account for the shaping and formatting of the Congolese experience as mediated content, and from there, perhaps, to point out gestures of fine tuning or reformulation towards the aesthetics and expectations at the heart of the media qua institution. Such reflections occupied, indeed, a good part of the debate, in the context of a more general discussion on the forging of reality through media communications (this is a relevant topic; I shall come back to it in the next section). However, that line of inquiry tells us nothing about North Kivu, but about how highly modernized societies engage with Central African states of affairs from a distance. In order to engage mediatization in the Democratic Republic of Congo, the realities and institutions of the latter, including its communicational culture and media landscape, must be acknowledged. Furthermore, the 'starting point of the movie' adds another layer of specificity: choosing the perspective of the deaf caught in the Congolese war demands close attention to the meaning that life experience acquires for that particular community in such a complex setting.

Could mediatization cope with the case set forth by Spanò? Or is mediatization assuming just too much in its claims and hence doomed to fail? The answers came along soon enough. Yes: being a middle-range theory prudently defined as concerned with high modernity, the institutional approach to mediatization is in a position to account for such a state of affairs. Concretely, this can be achieved by 1) analyzing the unique ways of Congolese communication and the position of the available media within that specific social constellation, and 2) highlighting the differences between that and other coexisting settings, e.g. that of highly modernized societies. No: the historiographical and empirical facts furnishing the basics of mediatization theory do belong within certain historical and cultural coordinates, but do not pretend to be universally valid. Instead, the idea is to 'stipulate general patterns of development within particular social institutions or cultural phenomena, and within specific historical periods in particular social and cultural contexts' (Hjarvard 2013: 3). That such patterns are discerned from the high modern Euro-American experience is not obtrusive, insofar as it is understood as one of the many realities that high modernity affords qua historical period.

The meso theoretical position reminds us, on the one hand, of notable philosophical efforts to promote the cultural/historical context as the sine qua non of any critical enterprise. Such an interest can be traced back in European philosophy to the end of the eighteenth century at least - say from Diderot's aesthetics (Diderot [1772] 1996) to Marx's historical materialism (Marx [1859] 2009), to Adorno's cultural critique (Adorno [1955] 1983), to Foucault's archaeology of knowledge ([1966] 2012) and so forth. On the other hand, it also recalls ethnographical approaches to the rhetoric and linguistic elements of human praxis currently rising in certain philosophical quarters (Wilkins and Wolf 2012; Geertz 1973). The institutional take on mediatization involves, by definition, a relational understanding of the media vis-à-vis their institutional 
counterparts. In this vein, the notion of the middle-range stands out as a necessary methodological precaution, as well as an idoneous critical attitude towards experience overall. In terms of productive alliances, the crossfertilization of mediatization theory and other compatible trains of thought, of which the aforementioned are only a sample, can become instrumental in the consolidation of innovative approaches to media-related situations - an experiential set that, granted the ubiquity of the media (Adolf 2011: 156-158; Adorno 2009) and its viable conception as practice (Couldry 2004), could incorporate almost every aspect of contemporary human life.

\section{Groundwork for a critique of postmodern philosophy}

In chapter 2, Hjarvard goes on to develop the fundamentals of mediatization theory. There, media research in general is considered in the historical context of sociology as a modern academic discipline. In this connection, the media are said to have been left unaddressed by classical sociology in the nineteenth century because of their insufficient differentiation from other social institutions. Quite differently, Hjarvard sustains, the twentieth century landed us with states of affairs wherein the media are significantly embedded in a manifold of other institutions and, simultaneously, stand out as a semi-autonomous institutional compound. By that token, the argument goes, academia is now compelled to deal with the media as key definers of culture and society.

In that wake, the author presents the reader with an overview of the different meanings that the term 'mediatization' has acquired in previous scholarly works. In this account, earlier definitions also dwelled on the relation between the media and other institutions (politics, academia, science, religion, and so forth), mostly in terms of dependency and shaping. Still, the emphasis remains on the interactional, communicational aspect of the interplay. Although such accounts correctly underline the multifarious impact of the media, their explanatory bite may become less powerful in face of historical and cultural specificities, as previously commented. Here the meso level of analysis becomes conjoined with the institutional approach, because it is precisely in institutions, viz. the stratum of human activity in between the anecdotal specificity of the 'individual' and the abstract generality of 'society' as a decontextualized whole, where the unique cultural and historical coordinates of human experience show up with the greatest strength. In terms of its own cultural and historical situation, the process of mediatization is said to belong within, and be concerned with, high modern and highly modernized societies, where the media have attained an observable semi-autonomous character while remaining tightly intermingled with the operation of other social institutions.

Situating the process of mediatization at the heart of high modernity compels Hjarvard, in a sense, to take into account the postmodern views on the matter, considering that both theoretical corpora - mediatization theory and postmodern philosophy - deal with similar sets of historical processes. In this regard, the author emphatically distances his views from postmodern media theory, of which Baudrillard (1994) is taken to be the banner man. The criticism levelled at the ideas of the French thinker hinges on two main 
points: 1) the simplistic view that mediatization involves only one kind of transformation, and 2) the extreme ontological consequences such a transformation is said to have. Hjarvard states that the postmodern concept of mediatization is 'too simple, because it implies one single transformation, whereby mediated reality supplants experiential reality' and 'too grand in that it proclaims the disappearance of reality and the disintegration of distinctions, categorizations, that are fundamental to society and social cognition' (Hjarvard 2013: 15). The point at stake is fairly clear, namely that mediated reality is not all there is to reality, and that the total ontological collapse of high modernity is not to be taken for granted. Yet, the articulation contra Baudrillard leaves some interesting questions in the air.

The first point, i.e. whether or not postmodern theory is too narrow, stands out as an excellent starting point for critical discussion. I believe Hjarvard has a strong case here, as far as the complexity of the societal interplay surpasses by far the limits of experiential replacement. Nonetheless, a postmodern defence might unfold along these lines: the repercussion of the media 'code' over the ontological divisions into which praxis is articulated reaches all orders of collective and private life; therefore focusing on the ontological consequences of mediation is justified. A reply to this argument could be built up from the institutional perspective itself, for granting the media code full determining power over all normative institutional frameworks dismisses the semi-independent character of the media. In other words, that politics, religion, science, and the like may be said to be media dependent does not rule out the fact that the media themselves are embedded in the former too, which suggests a relation of mutual dependency. The subject is worth consideration.

The question regarding the broadness of postmodern theory is slightly more challenging. Certainly, the point is made that Baudrillard does not deny the existence of physical and social reality, but that it is a problem of representational substitution whereby the referent becomes disregarded (see Cole 1990). However, Hjarvard insists that postmodern mediatization proclaims the disappearance of experiential reality. In this vein, keeping with experience as the node of the discussion, a phenomenological defence of Baudrillard contra Hjarvard's terminology becomes available. Hjarvard distinguishes between mediated reality and experiential reality as the players in the game of reality replacement. From a Husserlian perspective, this distinction can be dissembled via transcendental reduction, which compels to focus on the sphere of consciousness without regard to the actual existence of the objects of experience (Husserl 1983: §33, see Hintikka 1995). The theoretical moment of suspension of concerns about the world as matter of fact ( $\dot{\varepsilon} \pi \circ \chi \eta$ ) leaves us with immediate experience, instead of reality, as the playground wherein the mediated and the non-mediated are engaged by the Ego. This has a better fit with Baudrillard's characterization of the hyper-real as 'a real without origin or reality' (Baudrillard 1994: 1). Now then, that non-mediated reality dilutes in the waters of the virtual is possible only because media products are themselves available to human consciousness, exclusively so by means of sensuous interplay. Ergo, media realities ought to be experiential objects too, interconnected to a higher or lesser degree with their non-mediated counterparts. 
That the referent is declared inaccessible, or that it actually never existed, has no impact over that theoretical datum or the institutional implications of such coexistence. From this perspective, the distinction between mediated and experiential reality seems feeble, being more accurate, perhaps, one between the mediated and the non-mediated.

Instead of an argument for a res extensa supplanted by media content to the point of disappearance, Baudrillard's proposal can be read as a riddle of intentionality, wherein, amidst the abundance of experiential substance, mental acts are tendentiously directed to media texts - which in turn are meant by consciousness in quite specific ways. It is important to note that the close connection between mediated and non-mediated materials at the level of experience is not exclusive to highly abstract camps of philosophical theory. On the contrary, recent approaches to pressing political matters hereandnow seem to share the same impression. That is the case, for example, of Debrix and Barder's work on violence, horror and spaces of exception (2013). Very interestingly, the consequences of the link between the mediated and the non-mediated in this account highlights, simultaneously, the profound mediatization of political stratagems and the uncanny appearance of practical realities though the virtual itself - as opposed to their argued disappearance:

The virtual 'real possibility' of the exception (Guantanamo, Abu Ghraib) may also seek to draw our attention towards the idea of a supposedly unique, unusual, extreme or indeed 'exceptional' zone as if such a site were not the norm, or as if it were not supposed to be real or actualized anywhere else [...] whereas, once again, the exception may have already (virtually) become the rule. There is thus a strategic (geo)political dimension to the deployment of virtual [hyper-real] spaces that [...] Baudrillard's conceptualization of the virtual makes us aware of (Debrix and Barder 2013: 82, original emphasis)

The critical bite behind the postmodern position lies in the question for the forces driving the intentional bias towards the hyper-real, as regards directedness and meaning attribution, and with a view to the responsibility of the postmodern individual in those respects. Still, as Hjarvard correctly observes, it is not the case that the only objects of human cognition in postmodern times are media products. It is not the case, either, that the alleged collapse of postmodernity spells the equalization of all there is to the same virtual foothold, as if everything were fiction. The case seems to be one of semantic confusion instead, whereby the ontological/categorical grounds onto which interpretations of experience are erected turn out to be derived from the symbolic substance of the media. Whether or not mediatization theory and postmodern philosophy are on the same page in this regard is an interesting question that I shall leave open.

\section{Technology as Spatiotemporal Bender}

Taking Anthony Giddens' structuration theory as point of departure (Giddens 1984), Hjarvard defines institutions as 'the stable, predictable elements in modern society' that 'constitute the framework for human communication 
and action in a given sphere of human life, at a given time and place' (Hjarvard 2013: 21). In a more specific sense, institutions are thought of in terms of human groups, characteristically steered by implicit and explicit rules as well as tasked with the administration of authority and material resources. The media, on a par with any other social institution, display exactly the same kind of attributes. Nevertheless, they are said to be semi-independent, point that is brought home by means of a historical account of their progressive shift from instruments of other institutions, to cultural institutions, to their current status of semi-independent entities (2013: 23-27). Noteworthy, the timeline refers exclusively to the development of the mass media, which is in my view a weak point in Hjarvard's exposition. I shall not elaborate much on the matter, because it is not pertinent for the purposes in hand, and because it is not a fatal flaw in Hjarvard's reasoning. Still, I want to point out that the historical account of semi-independence is not convincing as an explanation pertaining to the media in general, not only in light of archaeological arguments (e.g. Carels 2015, in the previous volume of this journal) but also in Hjarvard's own terms. For instance, it hardly holds for the 'media types' presented in Hjarvard's Table 5.3 (2013: 116), i.e. receiving devices (TV sets), playback devices (mp3 players), recording devices (DVD recorders), processing devices (computers), services (internet access) and so on. Likewise, shifts in the institutional level of analysis, from organization to device, are sometimes made unexpectedly along the way, which becomes confusing at times. In any case, let it be noted that the present discussion will focus on the media as semi-independent institution (for I think they actually are), yet with an emphasis on their non-organizational aspects.

Let us consider, then, the most concrete features of the mediatization process. Hjarvard underscores some elements of previous media research relevant in this regard that are also latent in his own contribution (2013: 11-14, see 63-66). Medium theory as advanced by Marshal McLuhan (1987), Walter Ong (1982) and Joshua Meyrowitz (1986), and the media sociologies of John Thompson (1995) and Friedrich Krotz (2007), stand out as important currents of thought running through The Mediatization of Culture and Society. Such affiliations situate Hjarvard's distinctive definition of mediatization in a tradition that gives great importance to the technological aspect of mediation and its impact over communicational practices. That outlook contributes greatly to set the orbit of all subsequent discussions in the book.

'By the mediatization of culture and society we understand the process whereby culture and society to an increasing degree become dependent on the media and their logic', Hjarvard states (2013: 17). On the one hand, the media are said to be integrated into the vast majority of contemporary social institutions; on the other hand and notwithstanding this, they are said to hold a semi-autonomous institutional status of their own, whereby their norms, authority and resources become influential for those of other institutional compounds. Now then, since human interaction increasingly happens in a mediated fashion, a powerful media logic (Altheide 2012; Altheide and Snow 1979) rises as the institutional, aesthetic and technological modus operandi that structures such sort of social relations (2013: 17). This situation impacts human communication and action down to their definitional and 
teleological grounds. The institutional interconnections described above - and hence the mediatization of culture and society at large - rely on the power of the media to crystallize such interactions effectively through non-direct communication.

In that light, it is not surprising that the media are defined as technologies that allow for the spatiotemporal expansion of human communication and the subsequent accrual to its possible modalities (Hjarvard 2013: 19). In addressing this ontic, dimensional aspect of technology as space-time bender, Hjarvard joins a well-travelled path in the philosophy of communication - to which Empedocles has devoted serious attention (e.g. Hesselberth and Roos 2015). As regards modality, the media qua substance are said to gain specific social and aesthetic forms that eventually frame the uses they are given in diverse social situations and contexts (Hjarvard 2013: 19). In this connection, the distinction is made between direct (strong) and indirect (weak) mediatization, where the former refers to the conversion of formerly non-mediated interactions into mediated activity, whereas the latter spells the growing influence of media contents and devices over general social practices of all sorts. In a different vein, as regards space and time, the argument turns to debates on human perception.

Hinging on Gibson's ecological theory of perception (1979), Hjarvard proposes a theory of media affordances with a view to social interaction, in the sense of communicative as well as non-communicative action. Affordances are defined here as the potential uses of objects in virtue of their material characteristics, which define what is possible and what is not in terms of feasible actions involving the objects in question. Yet, the actualization of the object's potential use is said to depend on the 'characteristics of the human or animal that interacts with the object' (2013: 27). Along these lines, as Hjarvard observes, Norman (1990) adds perceived affordance to Gibson's theory, namely the 'user's psychological evaluation of the object in relation to his/her objectives' (Hjarvard 2013: 28) - including cultural conventions and interpretations. Based on the above, the media are characterized as technologies with 'affordances that facilitate, limit, and structure communication and action' (2013: 28).

With that idea in mind, and drawing on Thompson (1995), Hjarvard goes on to distinguish between non-mediated and mediated communication. That is a curious move, indeed, because the author starts from Thompson's differentiation of the modes of social interaction, which misses for a moment the non-communicational dimension of weak mediatization (Hjarvard 2013: 20). It is a flawless move, however, which I read as a fine-tuning of the analytic instrument to the conceptual tonality of communicative praxis. Regarding interactivity, the point is made that the possibilities for reaction in mediated communication are not equally distributed in all cases, but that chances for engaging in meaningful give-and-take are widely affordable for the media today. Even traditional mass communication is said to leave room for response a posteriori, communicative or otherwise, directed to the utterer or the corporative medium (mostly with the aid of digital ICT). On a more fundamental level of theorization, Hjarvard recalls the multifarious ways the media afford 
interaction across time and space, which is the key to understanding how they alter human interaction.

In this account, the media afford time-space expansions, multitasking, and simultaneity. In a rather administrative sense, they are said to allow actors to optimize interaction by increasing the control over their personal investment in social activities, especially those involving the acquisition of useful information. Being sociable, in terms of interaction for the sake of interaction (Hjarvard 2013: 146ff), is efficiently manageable via networked channels, but it is no longer a necessary preamble in order to engage in fruitful social interaction. This also involves higher control over information exchange. For instance, the impression of joviality or tiredness given to the interlocutor in a face-to-face conversation is subject to the enacting element in situ, whereas the same impression given off via instant messaging can be prepared and shaped in a more strategic fashion - yet more promptly than via old-school posted letters. This observation should not be misunderstood as a cynic ode to hypocrisy and inauthenticity (in terms of self-identical presentation or the lack thereof), but as a descriptive indication of the social distance and/or proximity that the media can afford. This situation goes hand in hand with the opening up of new spaces of communication and action, the restructuring of the social norms of acceptable behaviour for such spaces, and the emergence of new mechanisms of norm enforcement.

Following Hjarvard, diverse stages for social interaction, physical and nonphysical, become available with the technological bending of space and time.

Hence a process of virtualization, quite different from that of the hyper-real, comes to pass:

Earlier, institutions were more bound to specific places [...] As a consequence of the intervention of the media, individuals can take part in and partake of many different social institutions, irrespective of their physical location.

(Hjarvard 2013: 33)

Virtualization is said to structure a new social geography, where the space-time formations of the individual, the local, the national and the global host interconnected flows of communication and action (2013: 36). This is, in my view, the most salient outcome of media technology as spatiotemporal bender, and the most formidable aspect of mediatization theory as Hjarvard conceives it. Worked out and enhanced since its introduction to the Anglophone community in 2008, the version presented in The Mediatization of Culture and Society presents the reader with a fully-fledged device whereby macro processes, such as individualization and globalization, can be efficiently discerned in light of the (reformulated) spatiotemporal coordinates of high modernity. The structuring consequences of the media affordances over human interaction - of which virtualization is a case in point - are unequivocal signs of the mediatization of culture and society on the micro-social level, Hjarvard maintains (2013: 37). The plausibility of this elaboration is hard to resist.

I would like to conclude by drawing attention to a crucial facet of mediatization 
theory that falls beyond the scope of the present exposition. The constitution of virtual spaces for communication and action are fundamental, also,

for the consolidation of the macro-level of mediatization evident in the structuring impact of the media over inter-institutional interaction. This aspect of the theory moves away from the ontic features of technology into the heart of its ontological agency. Here, I cannot begin to do justice to such an important aspect of mediatization theory. I content myself with this brief mention and an invitation to look into it with a critical eye.

\section{References}

Adolf, M. (2012), 'Clarifying mediatization: Sorting through a current debate', Empedocles: European Journal for the Philosophy of Communication, 3: 2, pp. 153-175, http://search.ebscohost.com/login.aspx?direct=true \&db $=$ ufh \&AN=86379755\&site=ehost-live. Accessed 24 June 2015.

Adorno, T. W. (2009), Current of Music: Elements of a Radio Theory, 1st ed., Malden: Polity Press.

Adorno, T. W. (1983), Prisms, Cambridge, MA: MIT Press.

Altheide, D. L. (2012), 'Media logic and social power', Empedocles: European Journal for the Philosophy of Communication 3: 2, pp.119-136, at: http:// search.ebscohost.com/login.aspx?direct $=$ true \&db=ufh \&AN=86379754\&si te $=$ ehost-live . Accessed 24 June 2015.

Altheide, D. L., and Snow, R. P. (1979), Media logic, Beverly Hills: Sage. Baudrillard, J. (1994), Simulacra and Simulation, Ann Arbor: University of Michigan Press.

Carels, E. (2015), 'Short notice', Empedocles: European Journal for the Philosophy of Communication, 5: 1\&2, pp. 31-38, http://search.ebscohost.com/login. aspx $?$ direct $=$ true $\& \mathrm{db}=\mathrm{ufh} \& \mathrm{AN}=100749052 \&$ site $=$ ehost-live. Accessed 24 June 2015.

Cole, S. (2010), 'Baudrillard's ontology: Empirical research and the denial of the Real', International Journal of Baudrillard Studies, 7: 2.

Couldry, N. (2004), 'Theorising media as practice', Social Semiotics, 14: 2 , pp. 115-132, http://www.tandfonline.com/doi/abs/10.1080/103503304200 0238295. Accessed 12 June 2013.

Couldry, N. and Hepp, A. (eds) (2013), Conceptualizing Mediatization [special issue], Communication Theory, 23: 3.

Debrix, F. and Barder, A. D. (2013), Beyond Biopolitics: Theory, Violence, and Horror in World Politics, Abingdon: Routledge.

Diagne, M. (2005), Critique de la raison orale: les pratiques discursives en Afrique noire/Critique of Oral Reason: Discursive Practices in Black Africa, Paris: Karthala Editions, https://books.google.pl/books?id=gFIwHlkKmPEC\&pr

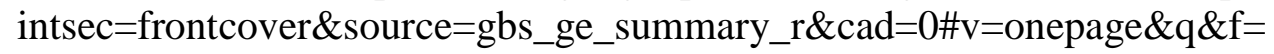
false. Accessed 19 June 2015.

Diderot, D. (1996), 'Traité du beau'/'Treatise on beauty', In L. Versini (ed.), Esthétique - Théâtre/Aesthetics - Theatre, Paris: Laffont, pp. 81-112. Foucault, M. (2013), The Order of Things: An Archaeology of Human Sciences, New York: Random House LLC, Vintage Books.

Geertz, C. (1973), The Interpretation of Cultures: Selected Essays, New York: Basic Books.

Gibson, J. J. (1979), The Ecological Approach to Visual Perception, Boston: Houghton Mifflin. 
Giddens, A. (2013), The Constitution of Society: Outline of the Theory of Structuration, Cambridge: John Wiley \& Sons.

Hepp, A., Hjarvard S. and Lundby, K. (eds) (2010), Mediatization - Empirical Perspectives [special issue], Communications, 35: 3.

Hesselberth, P. and Roos, C. M. (2015), 'Short Film Experience: Introduction', Empedocles: European Journal for the Philosophy of Communication, 5: 1\&2, pp.3-12. http://search.ebscohost.com/login.aspx?direct=true \&db=ufh\&A $\mathrm{N}=100749047 \&$ site=ehost-live. Accessed 24 June 2015.

Hintikka, J. (1995), 'The phenomenological dimension', In B. Smith and D. Woodruff Smith, (eds), The Cambridge Companion to Husserl, Cambridge: Cambridge University Press, pp. 78-105. http://universitypublishingonline. org/ref/id/companions/CBO9781139000703A007. Accessed 24 June 2015. Hjarvard, S. (2008), En verden af medier/A World of Media, Frederiksberg: Samfundslitteratur.

Hjarvard, S. (2004), 'From bricks to bytes: The mediatization of a global toy industry', In I. Bondebjerg and P. Golding (eds), European Culture \& the Media, Bristol: Intellect Ltd, pp. 43-63.

Hjarvard, S. (1999), 'Global media cultures : A research programme on the role of media in cultural globalization', Nordicom Review, 2, pp. 71-77. Hjarvard, S. (2013), The Mediatization of Culture and Society, Abingdon: Routledge.

Hjarvard, S. (2008b), 'The mediatization of society: A theory of the media as agents of social and cultural change', Nordicom Review, 29: 2, pp.105-134, http://www.nordicom.gu.se/sites/default/files/kapitel-pdf/269_hjarvard. pdf. Accessed 24 June 2015.

Hjarvard, S. (2004), 'The globalization of language: How the media contribute to the spread of english and the emergence of medialects', Nordicom Review, 25: 1\&2, pp.75-97. http://www.nordicom.gu.se/sites/default/files/ kapitel-pdf/157_075-098.pdf.

Hjarvard, S. and Petersen, L.N. (eds) (2013) 'Mediatization and cultural change [special section]', MedieKultur: Journal of Media and Communication Research, 29: 54, pp. 1-158.

Husserl, E. (1983), Collected works: General Introduction to a Pure Phenomenology 2, The Hague: Nijhoff.

Jensen, K.B. (2013), 'Definitive and sensitizing conceptualizations of mediatization', Communication Theory, 23: 3, pp. 203-222. http://onlinelibrary.

wiley.com/doi/10.1111/comt.12014/abstract. Accessed 24 June 2015.

Krotz, F. (2007), Mediatisierung: Fallstudien zum Wandel von Kommunikation, Wiesbaden: VS Verlag für Sozialwissenschaften, http://link.springer. com/10.1007/978-3-531-90414-6 Accessed 24 June 2015.

Marx, K. (2009), A Contribution to the Critique of Political Economy (ed. M.

Carmody), Marxists.org, http://www.marxists.org/archive/marx/works/ 1859/critique-pol-economy/. Accessed 13 January 2015.

McLuhan, M. (2003), Understanding Media: The Extensions of Man, critical ed., Corte Madera, CA: Gingko Press.

Meitz, T. (ed.) (2012), Media Processes [special issue], Empedocles: European Journal for the Philosophy of Communication, 3: 2.

Meyrowitz, J. (1985), No Sense of Place: The Impact of Electronic Media on Social Behavior, New York: Oxford University Press.

Norman, D.A. and Berkrot, P. (2011), The Design of Everyday Things, MP3 - 
Unabridged CD ed., Old Saybrook, CT.: Tantor Audio.

Ong, W. J. J. (2002), Orality and Literacy: The Technologizing of the Word, Abingdon: Routledge.

Spanò, A. (2013a), 'Director's statement: The Silent Chaos', Italy: Office

Number Four, http://www.officenumberfour.com/?page_id=347. Accessed

24 June 2015.

Spanò, A. (2013b), The Silent Chaos, Italy: Office Number Four.

Thompson, J.B. (1995), The Media and Modernity: A Social Theory of the Media, Cambridge: Polity Press.

Wilkins, R. and Wolf, K. (2012), 'The role of ethnography in rhetorical analysis: The new rhetorical turn', Empedocles: European Journal for the Philosophy of Communication, 3: 1, pp. 7-24.

\section{Suggested citation}

Roos, C. M. (2015), 'Mediatization theory: What is in it for the philosophy of communication? On Stig Hjarvard's The Mediatization of Culture and Society', Empedocles: European Journal for the Philosophy of Communication, 6: 1, pp. 91-103, doi: 10.1386/ejpc.6.1.91_1

\section{Contributor details}

Carlos M. Roos is currently pursuing doctoral research in Communication Sciences at Ghent University, Belgium, and in Philosophy of Art at Leiden University, the Netherlands. He teaches at the Department of Media Communications of Webster University Leiden. His research interests include metaphysics of art, critical theory and comparative philosophy.

Contact:

E-mail: c.m.roos.munoz@umail.leidenuniv.nl

Carlos M. Roos has asserted his right under the Copyright, Designs and Patents Act, 1988, to be identified as the author of this work in the format that was submitted to Intellect Ltd. 